\title{
Cutaneous larva migrans on the scalp: atypical presentation of a common disease*
}

\author{
Carolina Degen Meotti ${ }^{1}$ \\ Renata Anselme da Silva ${ }^{3}$ \\ Fred Bernardes Filho ${ }^{5}$
}

\author{
Glaura Plates ${ }^{1}$ \\ Karoline Silva Paolini ${ }^{4}$
}

\author{
Letycia Lopes Chagas Nogueira ${ }^{2}$ \\ Elias Moreira Nunes ${ }^{1}$
}

Abstract: Cutaneous larva migrans is a pruritic dermatitis due to the inoculation of helminths larvae in the skin, and it often occurs in children in tropical and subtropical areas. The authors describe an atypical case of cutaneous larva migrans in a 11 year-old child with scalp involvement, an unusual topography for this lesion.

Keywords: Larva migrans; Scalp; Scalp dermatoses

\section{INTRODUCTION}

Cutaneous larva migrans (CLM), also known as "migrant linear epidermitis", "beach worm", "migrant helminthiasis", "dermatitis serpiginosus", "creeping eruption" or "sand worm" is a zoodermatosis caused by cutaneous penetration of helminth larvae, usually parasites of the small intestines of cats and dogs. ${ }^{1}$ It is a common occurrence in tropical and subtropical countries and in people who visit beaches or sandy terrains which are polluted with feces of dogs and cats. ${ }^{2}$

Clinically it is characterized by the presence of intensely pruritic erythematous tunnels of linear and serpiginous character. From the point where there is larva penetration, tunnels are formed that usually draw an irregular and capricious path, progressing 2 to $5 \mathrm{~cm}$ per day. ${ }^{1,3}$ Sometimes, the wiggling line is restricted to a small area and in others, it extends itself like the drawing of a map. The lesion topography usually depends on the area which is in wider contact with the ground, like feet, legs or gluteal regions. ${ }^{1,4}$

According to the literature, scalp involvement by CLM is rare, as shown in a review of 158 cases of the disease, none of which presented scalp lesions. ${ }^{1,5,6}$ The number of larvae and, therefore, the number of inflammatory linear routes varies from a single one to tens or hundreds of them. ${ }^{1,4}$ The authors report a case of cutaneous larva migrans on scalp with the objective of demonstrating an atypical presentation of the disease.

\section{CASE REPORT}

Male patient, 11-year-old, was admitted presenting intense pruritus on elbows, legs and scalp for approximately two weeks. He denied previous treatment and comorbidities. He reported practicing recreational activities on the beach, like soccer, every weekend. At the dermatological exam, we observed the presence of hair rarefaction on the left parietal region, with an erythematous string of serpiginous and irregular path in its center (Figure 1); eczema-like lesions of linear and angular path on anterior lateral face of the distal-third of the left leg, ankle and foot (Figure 2).

The clinical characteristics of the lesions and epidemiological history with weekly activities on beach sand are very suggestive for the diagnose of cutaneous larva migrans. Therefore, considering the diagnosis, a treatment was prescribed with a single dose of ivermectin $6 \mathrm{mg}$ and tiabendazole ointment, $50 \mathrm{mg} / \mathrm{g}$, 3x per day for 7 days. A clinical cure was achieved after one week of use of the drugs.

\footnotetext{
Received on 18.07.2013.

Approved by the Advisory Board and accepted for publication on 02.08.2013.

Work performed in a Private Clinic - Rio de Janeiro (RJ), Brazil.

Conflict of interest: None

Financial funding: None

Private Clinic - Rio de Janeiro (RJ), Brazil.

Universidade Gama Filho (UGF) - Rio de Janeiro (RJ), Brazil.

Universidade Federal do Rio de Janeiro (UFRJ) - Rio de Janeiro (RJ), Brazil.

Universidade de Nova Iguaçú (UNIG) - Itaperuna (RJ), Brazil.

Instituto de Dermatologia Professor Rubem David Azulay, Santa Casa da Misericórdia do Rio de Janeiro (IDPRDA / SCMRJ) and Pontifícia Universidade Católica do Rio de Janeiro (PUC-RJ) - Rio de Janeiro (RJ), Brazil. 


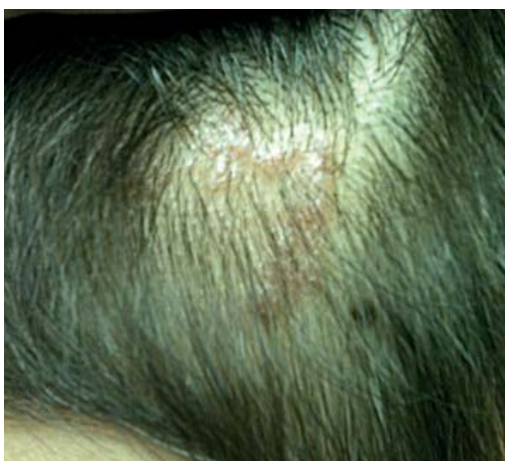

Figure 1:

Erythematous string of sinuous and irregular path on the left parietal region
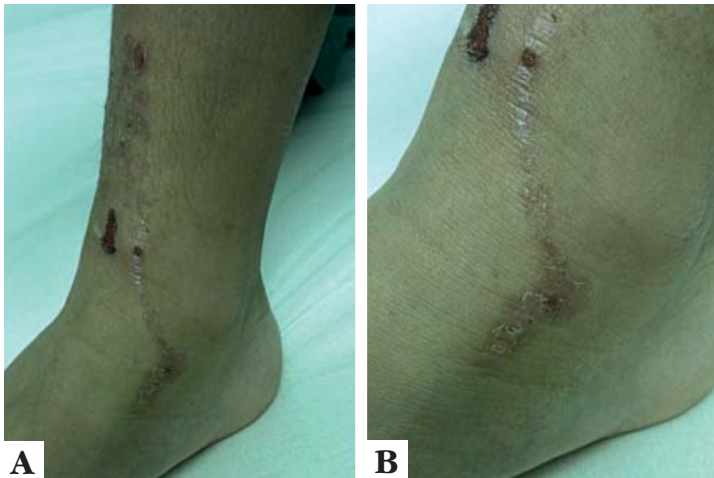

FigURE 2: (a) Erythematous and eczematoid lesions of linear and angular path located on the lateral anterior of the distal-third of the left leg, ankle and foot

\section{DISCUSSION}

The main species responsible for the clinical picture of CLM are Ancylostoma caninum and Ancylostoma braziliense, with both species presenting approximately $1 \mathrm{~cm}$ of length. ${ }^{1,2}$ Among the agents that can also cause the disease are other parasitic larvae of dogs and cats, such as Uncinaria stenocephala, Ancylostoma tubaeforme, Gnathostorna spinigerum and some strains of Strongyloides stercoralis; bovine parasites, Bunostornum phlebotomum; rodents parasites, Strongyloides myopota$m i$ and of wild dogs, Strongyloides procyonis. Larvae of Gasterophilus and Hypoderma flies and ants of Solenopis geminata species may also cause the same clinical manifestations. ${ }^{1,7,89}$ Another parasitic larva of dogs that deserves emphasis is the species Toxocara canis, which on men can cause visceral and ocular larva migrans. ${ }^{1,3}$

The diagnosis is based on clinical history, on the serpiginous and migratory aspect of lesions, which may be made more difficult by eczematization and secondary infections ${ }^{1,10}$ In the present case, the clinical diagnosis of CLM was considered by association of clinical characteristics, intense pruritus and history of frequent recreational activities on beach sand.

Depending on the number of lesions and their localization, the treatment can be topical or systemic. The drugs of choice are: albendazole $400 \mathrm{mg}$ / day for 3 days, ivermectin $200 \mathrm{mcg} / \mathrm{kg}$ in a single dose or tiabendazole $25 \mathrm{mg} / \mathrm{kg} /$ day, divided into two doses for 5 days. If there are few lesions, the tiabendazole ointment or cream $10 \%$ may be used. ${ }^{1,4}$ Due to posological convenience and considering greater compliance to the treatment with a single oral dose, ivermectin was indicated as the drug of choice. The association of the topical drug was the option of the authors to ensure fast improvement of the pruritus.

We consider of fundamental importance for a correct diagnosis and adequate treatment that dermatological semiology be carefully conducted. The publication of this clinical case is of interest because the patient presented CLM in an uncommon topography. Concomitant typical lesions on other sites facilitated the diagnosis. [

\section{REFERENCES}

1. Kalil CLPV, Webber A. Zoodermatoses. In: Ramos-e-Silva M, Castro MCR, editores. Fundamentos de Dermatologia. Rio de Janeiro: Atheneu; 2010. p.1055-7.

2. Rey L. Parasitologia: Parasitos e Doenças Parasitárias do Homem nas Américas e na África. 3.ed. Rio de Janeiro: Guanabara-Koogan; 2001. 856 p.

3. Lupi 0. Infections, Infestations and bites. Cutaneous larva migrans. In: Bolognia JL, Jorizzo JL, Rapini RP, editors. Dermatology. 2nd. New York: Mosby Elsevier; 2008. p. $1276-83$.

4. Upendra Y, Mahajan VK, Mehta KS, Chauhan PS, Chander B. Cutaneous larva migrans. Indian J Dermatol Venereol Leprol. 2013;79:418-9.

5. Guimarães LC, Silva JH, Saad K, Lopes ER, Meneses AC. Larva migrans within scalp sebaceous gland. Rev Soc Bras Med Trop. 1999;32:187-9.

6. Saka B, Kombaté K, Mouhari-Toure A, Balaka A, Agbo YM, Tatoa M, et al Hookworm-related cutaneous larva migrans in dermatology departments in Lomé, Togo, between 2006 and 2011. Ann Dermatol Venereol. 2012;139:564-6.

7. Hochedez P, Caumes E. Hookworm-related cutaneous larva migrans. J Travel Med. 2007;14:326-33.

8. Bowman DD, Montgomery SP, Zajac AM, Eberhard ML, Kazacos KR. Hookworms of dogs and cats as agents of cutaneous larva migrans. Trends Parasitol. 2010;26:162-7.

9. Feldmeier H, Schuster A. Mini review: Hookworm-related cutaneous larva migrans. Eur J Clin Microbiol Infect Dis. 2012;31:915-8

10. Lesshafft H, Schuster A, Reichert F, Talhari S, Ignatius R, Feldmeier H. Knowledge, attitudes, perceptions, and practices regarding cutaneous larva migrans in deprived communities in Manaus, Brazil. J Infect Dev Ctries. 2012;6:422-9.

MAILING ADDRESS:

Carolina Degen Meotti

Rua Voluntários da Pátria, 445 / sala 702. - Botafogo.

22270-903 - Rio de Janeiro - RJ

Brazil

E-mail: carolmeotti@yahoo.com.br

How to cite this article: P Meotti CD, Plates G, Nogueira LLC, Silva RA, Paolini KS, Nunes EM, Bernardes Filho F. Cutaneous larva migrans on the scalp: unusual presentation in a typical clinical presentation. An Bras Dermatol. 2014;89(2):332-3. 